\title{
A espessura e o volume do córtex somatossensorial se associam com a presença e severidade da alodinia cutânea em pacientes com migrânea?
}

\author{
Nicoly Machado Maciel ${ }^{1}$ (D) , Gabriela Ferreira Carvalho ${ }^{\text {ID }}$, Natália Oliveira1 ${ }^{1 D}$, Carina Ferreira Pinheiro ${ }^{1}$ (D) \\ Fabíola Dach ${ }^{1}$ (D) Antônio Carlos dos Santos ${ }^{1}$ (i) , Debora Bevilaqua-Grossi' ${ }^{1}$ (D)
}

'Faculdade de Medicina de Ribeirão Preto, Universidade de São Paulo, Ribeirão Preto, SP, Brasil.

${ }^{2}$ Institute of Health Sciences, Department of Physiotherapy, University of Luebeck, Luebeck, Germany

\section{Introdução}

As alterações cerebrais presentes nos pacientes com migrânea tem sido muito estudadas nos últimos anos. A presença e a severidade da alodinia cutânea (AC) estão relacionadas a alterações funcionais e vasculares do cérebro. Todavia, a associação entre alterações estruturais do cérebro e a AC ainda não estão bem esclarecidas em pacientes com migrânea.

\section{Objetivo}

Avaliar a correlação entre a presença e severidade da AC, as características da migrânea, e a espessura e o volume do córtex somatossensorial.

\section{Material e Métodos}

Nesse estudo transversal, foram incluídos 45 pacientes com migrânea com e sem aura e migrânea crônica, diagnosticados por neurologistas especialistas em cefaleias. Os voluntários preencheram o Questionário de Sintomas de Alodinia (ASC-12 / Brasil) e fizeram uma avaliação encefálica por meio de ressonância magnética (RM). As imagens foram inspecionadas por neurorradiologista cego e processadas no software Freesurfer. Este projeto foi aprovado pelo comitê de ética local (processo nº 13068/2015).

\section{Resultados}

Testes de correlação e modelo de regressão linear foram usados para avaliar a relação entre os desfechos. Não foi observada correlação significativa entre a espessura e o volume do córtex somatossensorial com o ASC-12/Brasil (espessura: $r=-0,16$; volume: $r=0,22 ; p>0,05$ ), frequência (espessura: $r=-0,10$; volume: $r=0,14 ; p>0,05$ ) ou início da migrânea (espessura: $r=-0,06$; volume: $r=0,12 ; p>0,05$ ). A espessura e o volume do córtex somatossensorial não foram diferentes entre os subgrupos de migrânea $(p>0,05)$. A variabilidade dos escores do ASC-12/Brasil não pode ser prevista pela espessura $(p>0,05)$ ou volume $(p>0,05)$ do córtex somatossensorial. Estudos futuros associando o uso de questionários com medidas quantitativas térmicas e mecânicas são recomendados.

\section{Conclusão}

Os resultados mostram que a morfologia do córtex somatossensorial não está associada nem com AC nem com características da migrânea nessa população.

Palavras-chave: Transtornos de Enxaqueca, Sensibilização do Sistema Nervoso Central, Córtex Somatossensorial, Ressonância Magnética. 